\title{
Los artículos científicos como herramienta de aprendizaje en las escuelas de arquitectura
}

\section{Carolina Rodríguez-Ahumada}

Universidad Católica de Colombia, Bogotá (Colombia)

Facultad de Diseño, Programa de Arquitectura

Rodríguez-Ahumada, C. (2018)

Los artículos cientííicos como

herramienta de aprendizaje en las

escuelas de arquitectura Revis-

ta de Arquitectura (Bogotá)

20(2), 3-9. doi: http://dx.doi.

org//0.14718/RevArq.2018.20.2.216

doi: http://dx.doi.org/10.14718/RevArq.2018.20.2.2161

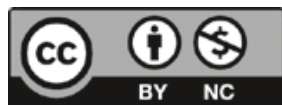

\author{
Arquitecta, Universidad Católica de Colombia, \\ Bogotá. \\ Especialista en Gerencia de Obra, Universidad \\ Católica de Colombia, Bogotá. \\ Magíster en Arquitectura, Universidad Nacional \\ de Colombia, Bogotá. \\ Editora de sección Proyecto Arquitectónico y \\ Urbano en la Revista de Arquitectura. \\ (D) https://orcid.org/0000-0002-3360-1465 \\ crodrigueza@ucatolica.edu.co
}

\section{Resumen}

Se propone un aporte a las reflexiones sobre la enseñanza, mediante el reconocimiento de los artículos científicos como herramienta de aprendizaje en las escuelas de arquitectura. Para ello, se recopilaron algunos documentos de índole teórico sobre la formación del arquitecto, cartas y acuerdos de organizaciones internacionales, publicaciones de trabajos estudiantiles y artículos de reflexión sobre la enseñanza. Asimismo, se realizó la ponderación de datos porcentuales sobre las temáticas disciplinares presentadas en los tres últimos años de publicación de la Revista de Arquitectura. En consecuencia, se enfatiza sobre la importancia del hacer en la formación del pensamiento, y se sugiere la aplicación de una metodología de trabajo académico de acompañamiento, basada en los procesos de escucha, diálogo, experimentación y reflexión, como acciones indispensables en los desarrollos proyectuales. Por último, se resalta la importancia del abordaje de los artículos científicos como ejercicio promotor del debate cognitivo y de actualidad en las aulas.

Palabras clave: alfabetización científica, conocimiento científico, difusión de conocimientos, enseñanza de la arquitectura, investigación aplicada, investigación formativa.

\section{Scientific articles as a learning tool in architecture schools}

\section{Abstract}

This paper aims to contribute to reflections on teaching, through the recognition of scientific articles as a learning tool in architecture schools. To this end, theoretical documents on the training of architects, letters and agreements of international organizations, publications of student works, and reflection articles about teaching were compiled. Likewise, weighted percentage data were presented on disciplinary topics published during the last three years in the Revista de Arquitectura. Consequently, the paper emphasizes the importance of "making" in thought formation, as well as it suggests the application of a complementary academic work methodology, based on processes of listening, dialogue, experimentation, and reflection, as fundamental actions in project development. Finally, it highlights the importance of using scientific articles as an exercise to promote cognitive and current debate in classrooms.

Keywords: Scientific literacy, scientific knowledge, dissemination of knowledge, teaching of architecture, applied research, formative research.

\section{Os artigos científicos como ferramenta de aprendizagem nas escolas de arquitetura}

\section{Resumo}

Propõe-se uma contribuição para as reflexões sobre o ensino, a partir do reconhecimento dos artigos científicos como ferramenta de aprendizagem nas escolas de arquitetura. Assim, foram recopilados alguns documentos de índole teórica sobre a formação do arquiteto, cartas e acordos de organizações internacionais, publicações de trabalhos estudantis e artigos de reflexão sobre o ensino. Além disso, foi feita a ponderação de dados percentuais sobre as temáticas disciplinares apresentadas nos três últimos anos de publicação da Revista de Arquitectura. Portanto, faz-se ênfase na importância da prática na formação do pensamento e sugere-se a aplicação de uma metodologia de trabalho acadêmico de acompanhamento, baseada nos processos de escuta, diálogo, experimento e reflexão, como ações indispensáveis nos desenvolvimentos de projetos. Por último, destaca-se a importância da abordagem dos artigos científicos como exercício da promoção do debate cognitivo e da atualidade nas aulas.

Palavras-chave: alfabetização científica, conhecimento científico, difusão de conhecimentos, ensino da arquitetura, pesquisa aplicada, pesquisa formativa.

\section{Introducción}

La formación del arquitecto permanece en debate. Entre variadas apreciaciones puestas en común en simposios y conferencias se han propuesto reflexiones sobre la importancia de formar arquitectos idóneos para ejercer la profesión. Sin lugar a dudas, estas reflexiones han estado a la par con las necesidades contemporáneas de la sociedad, lo cual ha establecido que constantemente las escuelas de arquitectura reformen sus maneras de actuación al respecto de la enseñanza (Ramírez, 2005), es por ello que el interés de este texto radica en brindar un aporte a estas reflexiones, mediante el reconocimiento de los artículos científicos como herramientas de aprendizaje en las escuelas de arquitectura. Estos documentos corresponden al interés global de generar la difusión del conocimiento a través de la inmediatez de la información, la cual debe ser presentada de manera clara, estructurada y, actualmente, vinculada a los medios de difusión electrónica, lo que contribuye, cada vez más apresuradamente, a la red de información mundial.

Estos aportes, que requieren incesantes actualizaciones, proponen en la academia un escenario que demanda ser abordado mediante debates y discusiones, y que necesita de la participación, no solo del docente, sino también y en mayor medida del estudiante universitario. Es él quien de manera autónoma debe ahondar en la investigación, ejerciendo su rol de aprendiz curioso a favor del rastreo del conocimiento, con la finalidad de autoformarse y ser, desde ya, partidario de las inquietudes disciplinares.

Asimismo, y entendiendo que la autoformación estructura la pericia en los argumentos, la capacidad de teorizar y la efectividad en la experimentación, se parte del principio de la necesaria integralidad del arquitecto propuesta por Vitruvio (1992 [1761]) al anunciar especialmente los conceptos de significado y el significante como cuestiones básicas requeridas. 
Tiene, como las demás artes, principalmente la Architectura, aquellas dos cosas de significado y significante. Significado es la cosa propuesta á tratarse. Significante es la demostración de la cosa con razones científicas. Por lo que, parece debe estar ejercitado en ambas, el que quiera llamarse Architecto. Deberá, pues, ser ingenioso y aplicado; pues ni el talento sin el estudio, ni este sin aquel, pueden formar un artífice perfecto (Libro l, capítulo I, p. 3).

En efecto, el arquitecto debe su formación a la habilidad mental de construir pensamientos críticos, basados en conocimientos teóricos, pero también a la destreza aprendida y adquirida en lo empírico. Consecuentemente, en el escenario académico se requiere promulgar la generación de aulas científicas que estén conformadas por áreas de trabajo manual, discursivo y cognitivo, en las que el material de trabajo contemple no solo herramientas de dibujo e instrumentos tecnológicos, sino también documentos clásicos y, en gran medida, aquellos de reciente publicación, como la carta abierta, para incorporarse a los estados de discusión sobre los temas disciplinares.

No obstante, las escuelas deberán integrarse a estos planteamientos y debates mundiales, aislándose de la idea de una academia individualizada. Esta conexión mundial de la enseñanza inicia cuando se tiene conocimiento de las actuaciones y los avances cognoscitivos de las escuelas locales, regionales e internacionales, condición actualmente posible con los adelantos tecnológicos en materia de redes de comunicaciones interconectadas.

Esta red de información mundial brinda la oportunidad de ver los avances gráficos, procedimentales y experimentales en torno a la profesión, pero también permite el acceso a la lectura de documentos resultado de investigación que en un alto porcentaje se encuentran disponibles mediante el acceso abierto (Eligio-Triana, 2016). Por tanto, el conocimiento adquirido a través de estas redes de información inmediata permite construir avances de manera rápida y conjunta, en virtud del interés por aportar a los conocimientos mundiales sobre la disciplina, procurando desde la academia la respuesta de la profesión a las exigencias de las organizaciones internacionales a presente y futuro.

De esta manera, la lectura de los avances científicos locales en el campo arquitectónico le permite al lector una mayor aproximación a los casos de estudio actuales, influenciado por los intereses reales de las comunidades cercanas, las estadísticas o datos soportados desde variadas experiencias y métodos investigativos, con la finalidad de formar un criterio objetivo y poder reflexionar sobre el campo académico y profesional, mediante un proyecto arquitectónico.

Con ello, la ciencia apoyada en la academia, y la academia apoyada en la ciencia, requieren múltiples estrategias de aprovechamiento por docentes y estudiantes, teniendo en cuenta que la lectura no implica la aceptación de los planteamientos, pero sí la potestad para establecer una postura y formación de pensamiento crítico, requerido actualmente en cualquier tema del ámbito nacional e internacional.

De esta manera, la mayor herramienta de avance disciplinar en todas las profesiones implica ser parte de una red de información que permita avanzar más rápidamente sobre cuestiones que quizá ya vienen siendo estudiadas y que bajo una mirada alterna, incluso desde otra parte del mundo, pueden llegar a convertirse en soluciones de gran impacto.

\section{Metodología}

Esta reflexión se realiza a partir de una revisión documental de publicaciones relativas al aprendizaje, la teoría y la docencia, a las discusiones en reuniones profesorales sobre la actualización de las formas de enseñanza en las aulas de arquitectura, a las recomendaciones de formación que refieren las organizaciones internacionales, a las nacientes necesidades de autoformación y a los principios que contempla el ejercicio de divulgación de publicaciones con carácter científico.

Para ello se tuvieron en cuenta algunos documentos de índole teórico y reflexivo sobre la formación del arquitecto, especialmente en la categoría de Investigación ${ }^{1}$ de la 17 Anual de Estudiantes de Arquitectura, convocada por la Sociedad Colombiana de Arquitectos (SCA, 2017); de igual forma, textos y reflexiones de obras clásicas, cartas de organizaciones internacionales y artículos de reflexión sobre la enseñanza actual. Del mismo modo, se extrajeron datos porcentuales de las temáticas disciplinares presentadas en los tres últimos años de publicación de la Revista de Arquitectura, y se revisaron epistemológicamente algunos planteamientos que delimitan esta reflexión.

\section{Resultados}

\section{El proyecto desde la lectura de lo científico}

Según la Unesco (2011), la formación del arquitecto requiere de una mirada realista de actualidad, apoyada en la situación local, regional e internacional; esto es posible siempre y cuando se asuman posturas de experimentación en sitio y se aborden las investigaciones respectivas dentro del aula. Por consiguiente, para comenzar se debe recordar lo enunciado por Jorge Ramírez Nieto (2005) sobre la disimilitud ya vista desde hace una década entre los centros de investigación y los espacios de academia.

La creación de nuevo conocimiento proveniente de la investigación es un problema que se circunscribe, en la mayoría de los casos, al territorio -abierto- de las universidades y -cerrado- de los centros de investigación. Son estos dos universos que con frecuencia se perciben superpuestos pero que en la realidad viven procesos disímiles (p. 40).

Por tanto, la unificación entre el lenguaje de la comunidad investigativa y científica con el lenguaje en las aulas de clases, proyectos y talleres se reconoce como una necesidad que no ha llegado a una conciliación pragmática. Si bien socialmente el quehacer de los arquitectos se entiende como una acción que no es netamente intuitiva, no se ha hecho evidente la necesidad de abordar con mayor énfasis la consulta de bases de datos bibliográficas y, por ende, la lectura de artículos científicos, lo que ha causado una falla creciente en el manejo de la conceptualización y objetividad con la que deben ser tratados los distintos planteamientos de un grupo académico.

Por tal motivo, la visibilidad de estas investigaciones, ya sean básicas, aplicadas o de desarrollo experimental (OECD, 2015 , p. 45), debe permanecer a la par de los procesos y las necesidades profesionales de la arquitectura para, también así, volver a la unificación de la academia con el quehacer arquitectónico, haciendo uso de la generación y el nuevo conocimiento. En consecuencia, la lectura de investigaciones

1 Conformada por tres subcategorías: 1) investigación previa al desarrollo del proyecto o "Investigación Proyectual", 2) tecnología y 3) teoría, historia y crítica. 
propende por el desarrollo de proyectos con posiciones críticas y reflexivas hacia la realidad inmediata, construyendo por efecto una posición profesional sobre los futuros intereses de investigación proyectual de los arquitectos en Latinoamérica.

De esta forma, la investigación se liga no solo a los intereses académicos cerrados o de estudiantes con inquietudes de estudios avanzados, sino también y en gran medida a la comunidad universitaria en general, proyectada a ejercerse profesionalmente en distintos campos de actuación; esto conlleva reconocer la distinción entre los aspectos de la investigación formativa y la formación en investigación, para lo cual se resalta el aporte de Ciro Parra (2004, p. 72), quien afirma que la primera es una estrategia pedagógica para el aprendizaje, mientras la segunda propende por brindar una estructura básica a favor de la indagación. Así, quien se forme en esta disciplina debe entender y ser ecuánime en ambos aspectos, adoptando metodologías de investigación que le permitan construir su propio conocimiento.

En consecuencia, este interés debe convertirse en la base de profesionalización básica que, encaminada a la concepción del espíritu científico al que Bachelard (2000) hizo referencia, permita la construcción del conocimiento mediante la opinión crítica y la acción empírica.

\section{El espíritu científico nos impide tener opinión sobre cuestiones que no comprendemos, sobre cuestiones que no sabemos formu- lar claramente. Ante todo, es necesario saber plantear los proble- mas. Y dígase lo que se quiera, en la vida científica los problemas no se plantean por sí mismos. Es precisamente este sentido del problema el que sindica el verdadero espíritu científico. Para un espíritu científico todo conocimiento es una respuesta a una pre- gunta. Si no hubo pregunta, no puede haber conocimiento cien- tífico. Nada es espontáneo. Nada está dado. Todo se construye (p. 16).}

Conforme a ello, la academia no puede estar inmersa en generalidades, suposiciones, en situaciones desactualizadas o simplemente en el hacer, sino que debe entremezclarse con hechos inmediatos de realidad como lo indican y requieren los Objetivos de Desarrollo Sostenible (ODS), que buscan a nivel internacional, y a nivel de Latinoamérica y el Caribe ${ }^{2}$, la coherencia y el entrelazamiento de los objetivos sociales con los educativos, y los científicos con los profesionales, como lo menciona la National Research Council.

In a world filled with the products of scientific inquiry, scientific literacy has become a necessity for everyone. Everyone needs to use scientific information to make choices that arise everyday. Everyone needs to be able to engage intelligently in public discourse and debate about important issues that involve science and technology 3 (1996, p. 1)

Adicionalmente, las Naciones Unidas plantean la convocatoria Hábitat III, realizada en el 2016 en Quito, que reúne investigadores, profesionales y estudiantes con una agenda de discusión, debate y planteamiento sobre las acciones por realizar al respecto de la vivienda y el desarrollo urbano sostenible en la región (UN-Hábitat, 2016); a su vez, entidades locales como Colciencias consolidan publicaciones como el Libro Ver-

2 Por medio del Proyecto Regional de Educación para América Latina y el Caribe (Prelac).

3 "En un mundo lleno de productos de la indagación científica, la alfabetización científica se ha convertido en una necesidad para todos: todos necesitamos utilizar la información científica para realizar opciones que se plantean cada día; todos necesitamos ser capaces de implicarnos en discusiones públicas acerca de asuntos importantes que se relacionan con la ciencia y la tecnología" (traducción propia). de 2030 (2018), en donde se plantean las políticas nacionales respecto a la ciencia y la innovación a favor del desarrollo sostenible en Colombia; todas ellas, temáticas básicas en los requerimientos de investigación y formación en arquitectura.

Ciertamente, es de señalar que las aproximaciones académicas de un taller de diseño deben lograrse desde los debates y las discusiones, como manera de aproximar la ciencia al aula de arquitectura, con la finalidad de lograr entornos investigativos con un lenguaje unánime y creciente, que pueda ser trasladado a congresos, simposios, investigaciones colaborativas, entre otros. Esta participación desde el aula de clase, y no solamente desde los grupos de investigación, procura que el concepto principal de la academia sea el de la reflexión, la posición crítica y resolutiva a favor del mejoramiento de la sociedad y de la profesión, como fue planteado en la carta de Budapest (1999):

\begin{abstract}
... que en el siglo XXI la ciencia debe convertirse en un bien compartido solidariamente en beneficio de todos los pueblos, que la ciencia constituye un poderoso instrumento para comprender los fenómenos naturales y sociales y que desempeñará probablemente un papel aún más importante en el futuro a medida que se conozca mejor la complejidad creciente de las relaciones que existen entre la sociedad y el medio natural (párr. 8).
\end{abstract}

Con todo, las aulas de clase demandan convertirse en aulas de ciencia a favor de la unificación de los saberes y de los procesos actuales llevados a cabo a nivel científico, indiscutiblemente pensados desde la mirada investigativa con la que los proyectos se ejecutan y desde la aproximación temática que la ciencia puede brindar al quehacer del arquitecto, principalmente desde su formación.

\section{El taller, hacer y pensar}

La estructura del planteamiento científico refiere a modelos de búsqueda, análisis y deducción, que pueden abordarse desde diferentes metodologías, pero deben realizarse con la mayor objetividad posible, entendiendo que la acción se basa en la información adquirida y cómo esta se puede llevar a reflexiones individuales y grupales a favor de la definición proyectual. Entonces, la principal estrategia de proyectación debe estar encaminada a realizar las observaciones necesarias, previamente a una ideación objetual, concibiendo un estado del arte y marco referencial que sea apoyado, a su vez, por el uso de artículos científicos que sitúen el pensamiento en las discusiones actuales, regionales e internacionales.

En consecuencia, será posible identificar aproximaciones con respecto a los siguientes interrogantes: ¿cómo se ha interpretado el problema?, ¿cómo se puede abordar? y ¿cuáles alternativas de solución existen?, uniéndose al debate de los investigadores y profesionales visibilizados por publicaciones en revistas indexadas o convocatorias disciplinares como las realizadas anualmente por la Sociedad Colombiana de Arquitectos, al convocar los resultados finales de carrera en las universidades colombianas, en la categoría de investigación, ${ }^{4}$ lo que extiende las posibilidades de abordaje discursivo con temas de estudio particularizados (Figura 1). Paralelo a ello, es posible revisar los intereses actuales de investigación, con especiales tendencias sobre estudios de casos urbanos, aproximaciones epistemológicas hacia

4 "Trabajos monográficos o experimentales que estudien y amplíen el conocimiento o la presentación de un proyecto con base en el método investigativo, rigor de procedimiento y presentación, aparte de los aportes de innovación y desarrollo" (SCA, 2017, p. 42). 

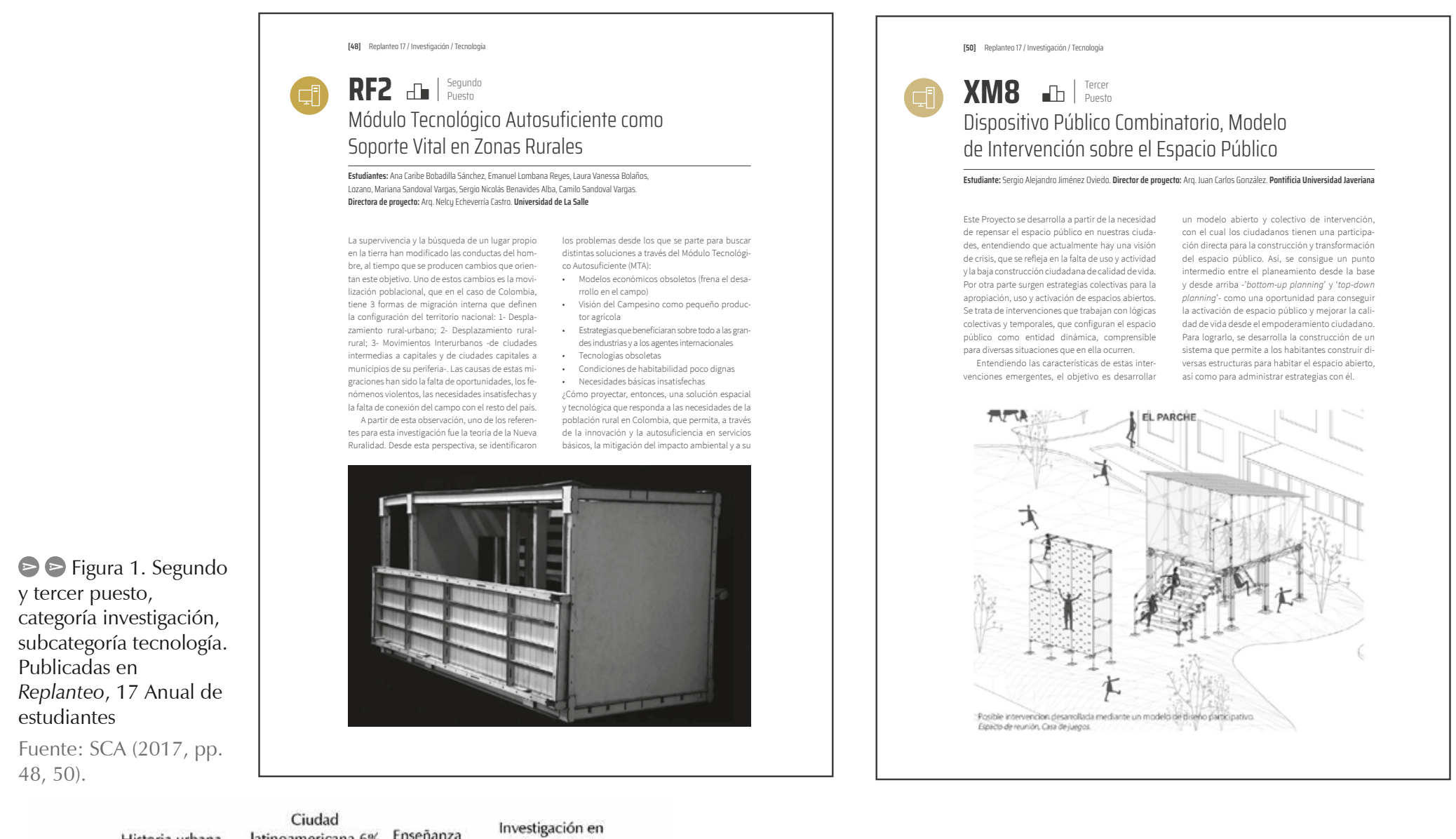

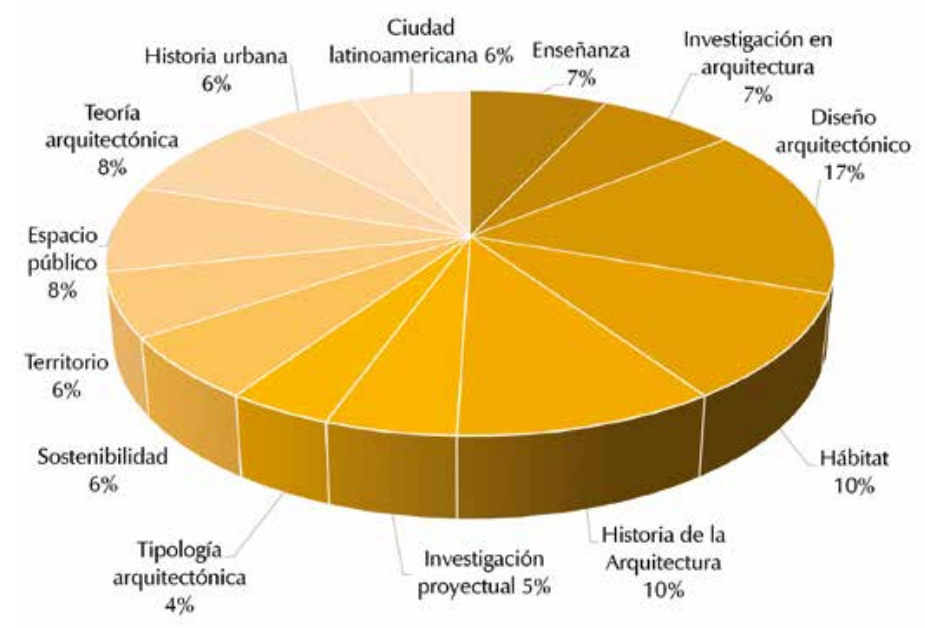

(A) Figura 2. Porcentajes temáticos de artículos publicados en la Revista de Arquitectura, de acuerdo con las palabras clave asociadas

Fuente: elaboración propia, basada en los datos recopilados en el Open Journal System (OJS) de la Revista de Arquitectura, 2018.

la arquitectura, análisis de variables compositivas en objetos arquitectónicos específicos o sobre la incorporación de nuevos sistemas técnicos en las actividades constructivas, como lo demuestran las temáticas con mayor demanda para publicación en la Revista de Arquitectura, durante los tres últimos años (Figura 2).

De igual manera, dentro de las muchas investigaciones posibles en arquitectura, existen casos particulares que denotan un interés por la revisión y el análisis proyectuales sobre obras ideadas o construidas por arquitectos con trayectoria profesional, lo cual contribuye a la generación de un respaldo cognitivo hacia la acción formativa y, consecuentemente, proyectiva (Figura 3).

En efecto, una vez es abordado un objeto arquitectónico como referente de investigación para el ejercicio proyectual, se requiere ver las características y los comportamientos físicos mediante la observación propia, pero también, y en gran medida, lo que otros han observado, analizado y expuesto sobre el mismo referente. Estos análisis pueden variar en indagación debido al interés analítico o incluso a la diferencia en la época en que fueron estudiados, por tanto, el lector queda inmerso en un panorama de discusión en el que de manera evaluativa participa para poder finalmente optar por generar alternativas resolutivas mediante el proyecto que concibe.

Cabe entonces resaltar que cada artículo trae consigo lo que Walter Benjamin Ilama constelaciones de conocimientos (2008 [1940]) formadas por variados documentos, desde textos clásicos hasta recientes aportes temáticos, lo cual permite que la lectura de los mismos se convierta en un dinámico enlazamiento de conocimientos que el estudiante debe dimensionar con apoyo del docente, como lo menciona Ramírez Nieto: "Allí, en la academia, el ámbito del conocimiento precedente (ahora muy frecuentemente denominado 'estado del arte') es una densa congregación de atmósferas que posibilita navegar en múltiples direcciones, dimensiones y amplitudes" (2005, p. 40), esto con el fin de ahondar de manera profunda en los intereses que a futuro regirán su labor intelectual y profesional.

Estas constelaciones están regidas por la inmersión del estudiante en el debate temático de su interés, lo que posteriormente lo llevará a participar activamente mediante el proceso de escucha y posterior diálogo, en donde dará razón de su punto de vista, y, finalmente, establecerá reflexiones que lo llevarán a experimentar (Figura 4).

A su vez, mediante la correlación entre las ciencias y el taller, es posible reflexionar, además, sobre cómo esta constelación de conocimientos se encuentra vinculada a métodos de difusión y exposición, lo cual puede llegar a brindar en la formación un esquema de trabajo con el cual se consoliden eficazmente los planteamientos. Estos métodos pueden ser recursivos a partir de la estructura básica de un artículo (introducción, metodología, resultados, discusión y conclusiones) y replicables en las actividades propias del diseño en el aula, con el fin de aprender sobre la necesaria claridad dentro los procesos creativos y, a su vez, acerca de los razonamientos que allí se elaboran (Figura 5). 


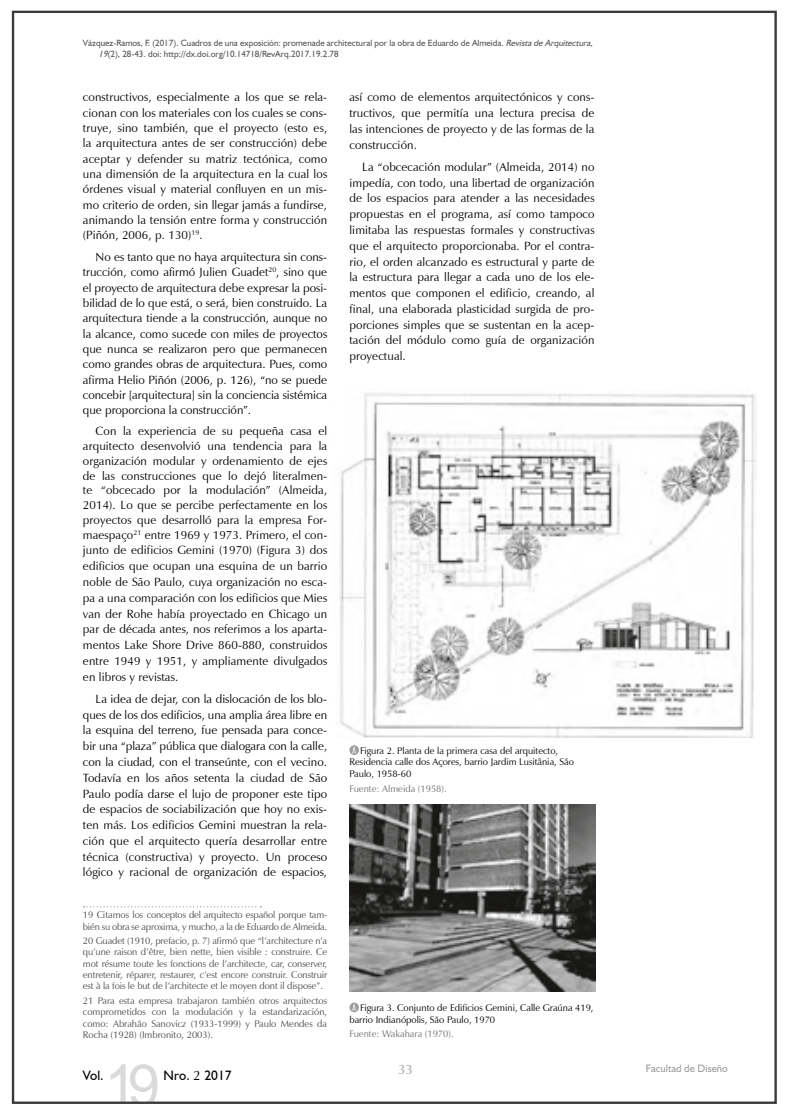

(4) (A) Figura 3. Extracto del artículo "Cuadros de una exposición: promedade architectural por la obra de Eduardo de Almeida" Fuente: Vázquez-Ramos (2017, pp. 33-34).

(1) Figura 5. Comparativo de los procesos de proyectación, artículo y aprendizaje basado en problemas

Fuente: elaboración propia, 2018, CC BY.
๑ Figura 4. Esquema analógico de una constelación cognitiva (escuchar), revisión (dialogar) y ejercicios proyectuales (experimentar) Fuente: elaboración propia, 2018, CC BY.

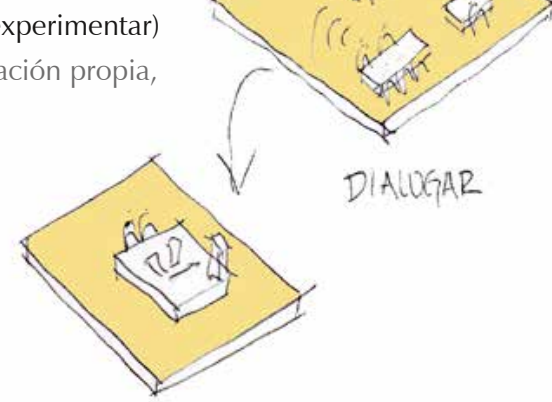

FIPERIMENTAR
Proceso proyectual (basado en las tres fases del proceso proyectual, presentado en la lección segunda: Análisis y proyecto (Quaroni, 1980 [1977])

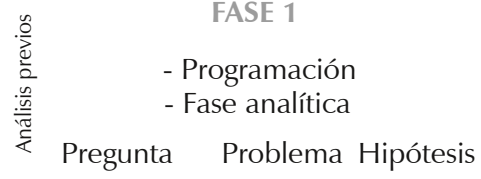

Introducción Metodología IMRYD (Metodología utilizada por la Revista de Arquitectura)
Aprendizaje basado en problemas ABP* (metodología adoptada por el Programa de Arquitectura de la Facultad de Diseño de la Universidad Católica de Colombia)

*Problem- Based Learning, metodología creada en la Facultad de Medicina de la Universidad de McMaster, Canadá (Morales y Landa, 2004).

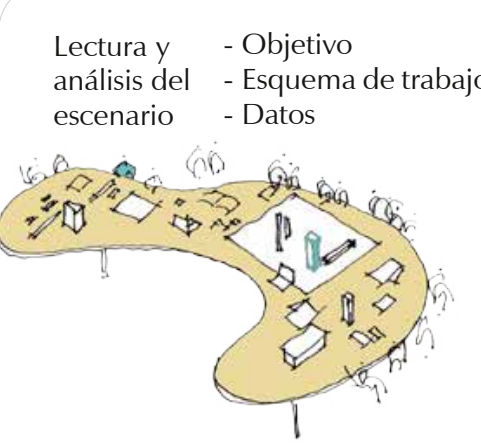

- Análisis

- Planteamiento Retroalimentación Evaluación

de resultados

- Experimentación

FASE 2

FASE 3

Proyectación

Planteamiento Pruebas Consideraciones

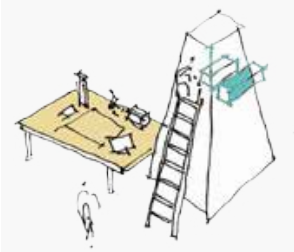

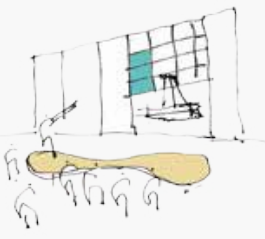

- Actuación

Realización/Gestión

Consideraciones desde la comunidad

Lectura/Debate Consideraciones desde la comunidad 


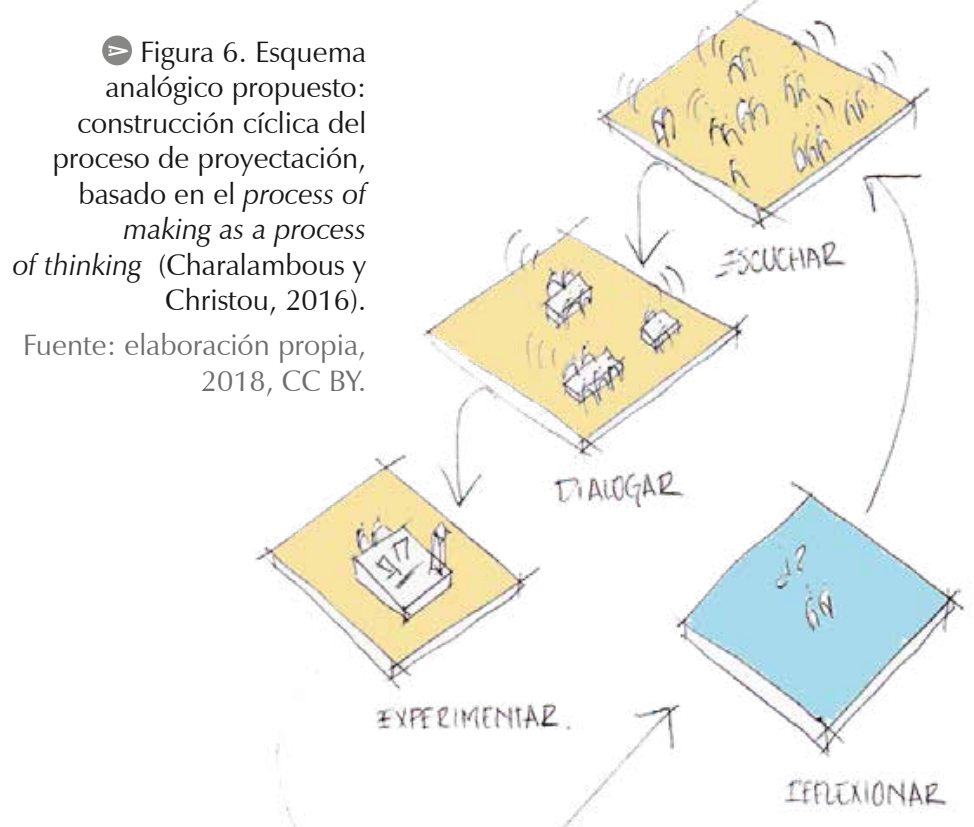

En consecuencia, se resalta el uso de la estructura de los artículos científicos como una estrategia que ayuda a clarificar el proceso de diseño, y motiva el proceso de hacer (construir) como un proceso de pensamiento (Charalambous y Christou, 2016), esto con el objetivo de posibilitar insistentemente un ejercicio simultáneo de lectura, debate y experimentación de manera continua, hasta lograr los resultados esperados proyectualmente, a fin de crear un ciclo de enriquecimiento en la formación del estudiante.

Through the design studio, patterns of the design process occur, that demonstrate an explorative way of learningby-doing, more specifically learning-by-making. This does not suggest the conventional way of understanding "making" as a way to represent or validate the "thinking process", but rather suggest a more dynamic approach that elaborates the process of making as a process of thinking 5 (2016, p. 377).

De manera conjunta, el proceso del hacer (elaborar o construir) ejecutado simultáneamente con el proceso de pensar, permite que el proyecto sea un procedimiento experimental en el que el autor tenga la posibilidad de aprender sobre sus propias acciones, soportado en la idea del hacer con el fin de pensar y pensar con la finalidad de hacer (Charalambous y Christou, 2016, p. 377), así, cada acción realizada se respalda en un estudio y reflexión teórica, al igual que cada teoría se apoya en la práctica.

A partir de lo anterior, el hacer no puede ser entendido como un resultado o producto final del pensamiento, sino como un actuar paralelo, ya que mediante este ejercicio dual se logran encausar las acciones $y$, a su vez, generar espontaneidad asentada en escenarios de reflexión y experimentación continua, esto vinculará al estudiante a un proceso de escucha, debate y experimentación que lo llevará finalmente a reflexionar $y$, posteriormente, requerir iniciar de nuevo el proceso para profundizar o clarificar ideas (Figura 6).

A partir de lo anterior, "tal enfoque metodológico, hacer para pensar, implica observación, improvisación y ejecución" (Charalambous y Christou, 2016, p. 377), por tanto, la metodología de trabajo puede incorporar la lectura y la observación como mecanismos de escucha y diálogo, y, finalmente, la constatación sobre la marcha como operatividad en el ejercicio de la experimentación.

5 "A través del estudio de diseño se producen patrones en el proceso de diseño, que demuestran una forma exploratoria de learningby-doing, más específicamente learning-by-making. Esto no sugiere la forma convencional de entender 'hacer' como una forma de representar o validar el 'proceso de pensamiento', sino más bien sugiere un enfoque más dinámico que elabora el proceso de hacer como un proceso de pensamiento" (traducción propia).
A menudo se recurre a la teoría como un ámbito de verdades autónomas, capaz de sobrevivir sin ningún sobresalto que plantee la práctica: así, quienes se dedican a "la teoría" suelen verlo como una alternativa inmaculada de la práctica. No; a eso le llamo práctica discursiva, capaz de desarrollarse con independencia de la arquitectura, como se ha visto en las últimas décadas, pero sin otra incidencia en el proyecto que el efecto negativo de inhibir el juicio (Piñón, 2016, p. 8)

Estos procesos requieren de la interacción grupal para alcanzar los objetivos en escenarios reales. Por ende, ambos propenden por el trabajo en equipo y la colaboración dinámica entre diversos actores $y$, al igual que las investigaciones, si no son dadas a conocer probablemente no puedan llegar a niveles más avanzados y, en consecuencia, no puedan ser de mayor utilidad.

\section{Discusión}

Conforme a lo planteado en uno de los objetivos de la Revista de Arquitectura, a partir del cual se busca "potenciar la discusión de experiencias e intercambios científicos entre investigadores y profesionales", se plantea un marco de encuentro entre los distintos niveles de formación y profesionalización que busca conectar al investigador con el escritor y, finalmente, con el lector, recordando que,

Sin duda, la mayoría de las personas habrá oído esta pregunta: si un árbol cae en un bosque y no hay nadie que lo oiga caer, ihace ruido? La respuesta correcta es "no". El sonido es algo más que "ondas de presión" y, en realidad, no puede haber sonido sin un oyente (Day, 2005, p. 1).

A partir de ello, el proyecto prima en la medida en la que se va construyendo como una fuente de conocimiento inagotable, que puede llevar a transformarse de manera continua mediante la experimentación y la contextualización investigativa. Esta fuente de conocimiento debe transmitirse claramente y sin limitaciones de lectura, sin restricciones y con asequibilidad, de tal manera que sea posible incentivar la reflexión en torno a los temas tratados y ampliamente estudiados por quienes los exponen, a fin de construir una red de información aplicable sobre la práctica y dentro de las aulas.

La investigación académica crea nuevo conocimiento porque da cuenta de la vida, se nutre de emociones y relatos, genera y se explica a través de imágenes, es decir, a través de la producción de estímulos que tocan aquellas percepciones que guardamos $y$, algunas veces, llevamos olvidadas en nuestro interior (Pérgolis y Valenzuela, 2013, p. 3)

Es por ello que lo transmitido por investigadores establece una interacción con lo existente y estructura las pautas para una investigación propia, con repercusión no solamente en el producto como proyecto, sino también en la mentalidad de quien lo produce; de esta manera se inhibe el estancamiento del crecimiento espiritual, como lo menciona Bachelard (2000) al explicar que "llega un momento en el que el espíritu prefiere lo que confirma su saber a lo que lo contradice, en el que prefiere las respuestas a las preguntas. Entonces el espíritu conservativo domina, y el crecimiento espiritual se detiene" (p. 17). Así que, si se permite que el proyecto se convierta en un acto obstinado y lineal ${ }^{6}$, se pueden llegar a limitar las

6 Véase también la explicación que al respecto hace Umberto Eco, cuando se refiere a "operaciones que habrán de ser actos de decisión responsable, de valoración ajustada de las formas, de sus elementos constitutivos, de las configuraciones que pueden asumir, y, por ello, de las bases ideológicas que las han de justificar. Objetos móviles y abiertos que con la variación del aparato retórico postulan la reestructuración del aparato ideológico, como la variación de las formas de uso conduce a una variación de la manera de pensar, de ver las formas en el contexto más amplio del obrar humano" (1986, pp. 277-278). 
posibilidades de crecimiento disciplinar y profesional, sin dar opción a la generación de lo no existente y, por ende, al conocimiento en las aulas.

\section{Conclusiones}

Es necesario precisar que, en la vinculación de estos saberes investigativos en la formación, se busca que el arquitecto ejerza como profesional con capacidad crítica e implicado en la solución de problemáticas reales, que requieren de ideas claras, precisas y mejoradas, por tanto, "mientras haya un sujeto capaz de reconocer, habrá un ojo que, a la vez que percibe una realidad existente, construye una realidad nueva" (Piñón, 2007, párr. 29). Luego, es el estudiante en el aula de clase quien, desde que inicia su formación, debe elaborar un pensamiento constructivo, edificando una academia desde lo que originalmente significa para la sociedad, es decir, como un escenario de discusión, debate, generación de nuevos conocimientos y análisis de avances investigativos que requieren aplicación en la sociedad.

A favor de esos nuevos conocimientos, se sugiere que en las escuelas de arquitectura en Latinoamérica se incursione en la participación científica, pero con más vehemencia desde las aulas de clase, para articular las preocupaciones locales con soluciones producto de la rigurosidad adquirida en los talleres, como lo mencionan Nadia Charalambous y Natasa Christou:
Integrative and investigative learning-by-doing approaches could undertake an experimental paradigm in which students and professors alike collaborate to push the boundaries of the discipline, allowing the pedagogical context to become central in the development of new insights ${ }^{7}$ (2016, p. 381).

Entre tanto, el aporte que los artículos científicos pueden brindarle a la academia desde los puntos de vista cognoscitivo, estructurante, reflexivo y resolutivo, será reflejo de los necesarios dinamismos y no estatismos en los procesos educativos. Para ello, se invita a que la atmósfera investigativa se extienda en los pasillos, las salas de reuniones, las aulas y las cafeterías de las academias, a favor de la construcción de una disciplina con intereses globales pero, sobre todo, locales y regionales, que brinde profesionales en arquitectura capaces de plantear reflexiones y soluciones reales a las situaciones de los países latinoamericanos.

Por tanto, el uso del conocimiento en la sociedad crea los lazos que fortalecerían la relación entre las escuelas de arquitectura y la sociedad, procurando aportes en todas las áreas de análisis. Así pues, una vez unificada la ciencia con la formación es posible establecer las bases que definirán al proyecto también como generador de nuevo conocimiento.

7 "Los enfoques integrativos e investigativos del aprendizaje mediante la práctica podrían emprender un paradigma experimental en el que estudiantes y profesores colaboren por igual para traspasar los límites de la disciplina, permitiendo que el contexto pedagógico se convierta en el centro del desarrollo de nuevos conocimientos" (traducción propia).

\section{Referencias}

Bachelard, G. (2000 [1938]). La formación del espíritu científico (23 ed.; B. Echeverría y J. Babini, trads.). México: Siglo Veintiuno.

Benjamin, W. (2008 [1940]). Tesis sobre la historia y otros fragmentos (B. Echeverría, trad.). México: Itaca.

Charalambous, N. y Christou, N. (2016). Re-adjusting the objectives of architectural education. Procedia - Social and Behavioral Sciences, 228, 375-382. doi: http://doi. org/10.1016/J.SBSPRO.2016.07.056

Colciencias (2018). Libro verde 2030. Política nacional de ciencia e innovación para el desarrollo sostenible. Resolución 0674 del 9 de julio de 2018. Política nacional de ciencia e innovación. Bogotá: Gobierno de Colombia. Recuperado de http://files.constantcontact.com/b884f834401/7cd9f0a0433d-4d55-9f24-5c8ffc82273b.pdf

Day, R. A. (2005). Cómo escribir y publicar trabajos científicos (3 ed. en español). Washington: The Oryx Press y Organización Panamericana de la Salud. Recuperado de http://www.smschile.cl/portal/documentos/varios/como_escribir_trabajos_cientificos.pdf

Eco, U. (1986 [1968]). La estructura ausente. (3 ed.; F. Serra Cantarell, trad.). Barcelona: Casa Editrice Valentino Bompiani \& C.S.

Eligio-Triana, C. (2016). Acceso abierto un compromiso de todos. Retos para el presente. Revista de Arquitectura, 18(1), 3-5. doi: http:// dx.doi.org/10.14718/RevArq.2016.18.1.1

Morales, P. y Landa, V. (2004). Aprendizaje basado en problemas / Problem-Based Learning (Revisión). Theoria, 13, 145-157. Recuperado de http://www.ubiobio.cl/theoria/v/ v13/13.pdf
National Research Council (1996). National Science Education Standards. Washington, DC: The National Academies Press. doi: https://doi.org/10.17226/4962

OECD (2015). Frascati Manual 2015: Guidelines for Collecting and Reporting Data on Research and Experimental Development. The Measurement of Scientific, Technological and Innovation Activities. Paris: OECD Publishing. doi: http://dx.doi. org/10.1787/9789264239012-en

Parra, C. (2004). Apuntes sobre la investigación formativa. Educación y Educadores, 7 , 57-77. Recuperado de http://educacionyeducadores.unisabana.edu.co/index.php/ eye/article/view/549

Pérgolis, J. y Valenzuela, J. (2013). El juego de los puntos o cómo evaluar una investigación en arquitectura. Revista de Arquitectura, 15(1), 3-5.

doi:http://dx.doi.org/10.14718/RevArq.2013.15.1.1

Piñón, H. (2007). Reflexión sobre la docencia de la arquitectura. Ponencia presentada en la Conferencia inaugural del $2 \underline{0}$ semestre de 2007, 03 de septiembre, Universidade Federal do Rio Grande do Sul. Recuperado de http://www.vitruvius.com.br/revistas/ read/arquitextos/08.089/195

Piñón, H. (2016). Arquitectura del proyecto. Escritos y Conferencias. Helio-Piñon.org. Recuperado de https://helio-pinon.org/escritos y conferencias/det-arquitectura_del proyecto_i71050

Quaroni, L. (1980 [1977]). Proyectar un edificio. Ocho lecciones de arquitectura. Madrid: Xarait Ediciones.

Ramírez Nieto, J. (2005). La investigación en la carrera de Arquitectura de la Universidad Nacional, 1937-1965. Una lectura de las actas de Consejo de la Facultad. Ensayos: Historia y Teoría del Arte, 0(10), 37-76. Recuperado de https://revistas.unal.edu.co/ index.php/ensayo/article/view/45830

Sociedad Colombiana de Arquitectos (SCA) (2017). 17 anual de estudiantes de arquitectura. Replanteo, 17, 42-55. Recuperado de http:// scabogota.org/wp-content/uploads/2018/07/ REVISTA-REPLANTEO-17.pdf

Unesco (2011). Carta Unesco/UIA de la formación en arquitectura. Tokio, Asamblea General de la Unión Internacional de Arquitectos. Recuperado de http://docplayer. es/12590963-Carta-unesco-uia-de-la-formacion-en-arquitectura.html

Unesco - ICSU (1999). Declaración de Budapest. Declaración sobre la Ciencia y el uso del saber científico. Conferencia Mundial sobre la Ciencia para el siglo XXI: un nuevo compromiso. Hungría: Unesco - ICSU. Recuperado de https://www.oei.es/histori$\mathrm{co} /$ salactsi/budapestdec.htm

UN-Hábitat (2016). Conferencia Habitat III. La nueva agenda Urbana. Quito: UN-Hábitat. Recuperado de http://habitat3.org/wp-content/uploads/Brochure-Español-Web-final. pdf

Vázquez-Ramos, F. (2017). Cuadros de una exposición: promenade architectural por la obra de Eduardo de Almeida. Revista de Arquitectura, 19(2), 28-43. doi: http://dx. doi.org/10.14718/RevArq.2017.19.2.78

Vitruvio, M. L. (1992 [1761]). Los diez libros de arquitectura (J. Ortiz y Sanz, trad.). Madrid: Akal. 


\section{Enfoque y alcance}

La Revista de Arquitectura (Bogotá) (ISSN 1657-0308 Impresa y E-ISSN 2357-626X en línea) es una publicación seriada de acceso abierto, arbitrada mediante revisión por pares (doble ciego) e indexada, en donde se publican resultados de investigación originales e inéditos.

Está dirigida a la comunidad académica y profesional de las áreas afines a la disciplina. Es editada por la Facultad de Diseño y el Centro de Investigaciones (CIFAR) de la Universidad Católica de Colombia en Bogotá (Colombia).

La principal área científica a la que se adscribe la Revista de Arquitectura (Bogotá) según la OCDE es:

Gran área: 6. Humanidades

Área: 6.D. Arte

Disciplina: 6D07. Arquitectura y Urbanismo

También se publican artículos de las disciplinas como 2A02, Ingeniería arquitectónica; 5G03, Estudios urbanos (planificación y desarrollo); 6D07, Diseño.

Los objetivos de la Revista de Arquitectura (Bogotá) son:

- Promover la divulgación y difusión del conocimiento generado a nivel local, nacional e internacional

- Conformar un espacio para la construcción de comunidades académicas y la discusión en torno a las secciones definidas.

- Fomentar la diversidad institucional y geográfica de los autores que participan en la publicación.

- Potenciar la discusión de experiencias e intercambios científicos entre investigadores y profesionales.

- Contribuir a la visión integral de la arquitectura, por medio de la concurrencia y articulación de las secciones mediante la publicación de artículos de calidad.

- Publicar artículos originales e inéditos que han pasado por revisión de pares, para asegurar que se cumplen las normas éticas, de calidad, validez científica, editorial e investigativa.

- Fomentar la divulgación de las investigaciones y actividades desarrolladas en la Universidad Católica de Colombia.
Palabras clave de la Revista de Arquitectura (Bogotá): arquitectura, diseño, educación arquitectónica, proyecto y construcción, urbanismo.

Idiomas de publicación: español, inglés, portugués y francés.

Título abreviado: Rev. Arquit.

Titulo corto: RevArq

\section{Políticas de sección}

La revista se estructura en tres secciones correspondientes a las líneas de investigación activas y aprobadas por la institución, y dos complementarias, que presentan dinámicas propias de la Facultad de Diseño y las publicaciones relacionadas con la disciplina.

Cultura y espacio urbano. En esta sección se publican los artículos que se refieren a fenómenos sociales en relación con el espacio urbano, atendiendo aspectos de la historia, el patrimonio cultural y físico, y la estructura formal de las ciudades y el territorio.

Proyecto arquitectónico y urbano. En esta sección se presentan artículos sobre el concepto de proyecto, entendido como elemento que define y orienta las condiciones proyectuales que devienen en los hechos arquitectónicos o urbanos, y la forma como estos se convierten en un proceso de investigación y nuevo de conocimiento. También se presentan proyectos que sean resultados de investigación, los cuales se validan por medio de la ejecución y transformación en obra construida del proceso investigativo. También se contempla la publicación de investigaciones relacionadas con la pedagogía y didáctica de la arquitectura, el urbanismo y el diseño.

Tecnología, medioambiente y sostenibilidad. En esta sección se presentan artículos acerca de sistemas estructurales, materiales y procesos constructivos, medioambiente y gestión, relacionados con los entornos social-cultural, ecológico y económico.

Desde la Facultad. En esta sección se publican artículos generados en la Facultad de Diseño, relacionados con las actividades de docencia, extensión, formación en investigación o internacionalización, las cuales son reflejo de la dinámica y de las actividades realizadas por docentes, estudiantes y egresados; esta sección no puede superar el $20 \%$ del contenido.

Textos. En esta sección se publican reseñas, traducciones y memorias de eventos relacionados con las publicaciones en Arquitectura y Urbanismo.

\section{A Frecuencia de publicación}

Desde 1999 y hasta el 2015, la Revista de Arquitectura (Bogotá) publicó un volumen al año, a partir del 2016 se publicarán dos números por año en periodo anticipado, enero-junio y julio-diciembre, pero también maneja la publicación anticipada en línea de los artículos aceptados (versión Post-print del autor).

La Revista de Arquitectura (Bogotá) se divulga mediante versiones digitales (PDF, HTML, EPUB, XML) e impresas con un tiraje de 700 ejemplares, los tiempos de

Universidad Católica de Colombia (2018,
julio-diciembre).
Revista de Arquitectura (Bogotá),
20(2), I-I28. Doi: I0.I47/8
ISSN: 1657-0308
E-ISSN: 2357-626X
Especificaciones:
Formato: 34 x $24 \mathrm{~cm}$
Papel: Mate II5 g
Tintas: Negro y policromía

producción de estas versiones dependerán de los cronogramas establecidos por la editorial.

Los tiempos de recepción-revisión-aceptación pueden tardar entre seis y doce meses dependiendo del flujo editorial de cada sección y del proceso de revisión y edición adelantado.

Con el usuario y contraseña asignados, los autores pueden ingresar a la plataforma de gestión editorial y verificar el estado de revisión, edición o publicación del artículo.
A Canje

La Revista de Arquitectura está interesada en establecer canje con publicaciones académicas, profesionales o científicas del área de Arquitectura y Urbanismo, como medio de reconocimiento y discusión de la producción científica en el campo de acción de la publicación.

\section{Mecanismo}

Para establecer canje por favor descargar, diligenciar y enviar el formato: RevArq FP20 Canjes 
Universidad Católica de Colombia

Presidente

Édgar Gómez Betancourt

Vicepresidente - Rector

Francisco José Gómez Ortiz

Vicerrector Jurídico

Edwin de Jesús Horta Vásquez

Vicerrector Administrativo

Édgar Gómez Ortiz

Vicerrector Académico

Elvers Medellín Lozano

Director de Investigaciones

Edwin Daniel Durán Gaviria

Directora Editorial

Stella Valbuena García

\section{Facultad de Diseño}

Decano

Werner Gómez Benítez

Director de docencia

Jorge Gutiérrez Martínez

Directora de extensión

Adriana Pedraza Pacheco

Director de investigación

Hernando Verdugo Reyes

Director de gestión de calidad

Augusto Forero La Rotta

Comité asesor externo

Facultad de Diseño

Édgar Camacho Camacho

Martha Luz Salcedo Barrera

Samuel Ricardo Vélez
Facultad de Diseño

Centro de Investigaciones - CIFAR
Revista de acceso abierto

arbitrada e indexada

Publindex: Categoría B. Índice Bibliografico Nacional IBN.

Esci: Emerging Source Citation Index.

Doaj: Directory of Open Access Journals.

Redalyc: Red de Revistas Cientificas de América Latina y el Caribe, España y Portugal.

SciELO: Scientific Electronic Library Online - Colombia

Redib: Red Iberoamericana de Innovación y Conocimiento Cientifico.

Ebsco: EBSCOhost Research Databases.

Clase: Base de datos bibliográfica de revistas de ciencias sociales y

humanidades.

Latindex: Sistema Regional de Información en Línea para Revistas

Cientificas de América Latina, el Caribe, España y Portugal (Directorio

y catálogo).

Dialnet: Fundación Dialnet - Biblioteca de la Universidad de La Rioja.

LatinRev: Red Latinoamericana de Revistas Académicas en Ciencias

Sociales $y$ Humanidades.

Proquest: ProQuest Research Library.

Miar: Matrix for the Analysis of Journals.

Sapiens Research: Ranking de las mejores revistas colombianas según visibilidad internacional.

Actualidad Iberoamericana: (Índice de Revistas) Centro de Informació Tecnológica (CIT).

Google Scholar

Arla: Asociación de Revistas latinoamericanas de Arquitectura.

Editorial

Av. Caracas $N^{\circ} 46-72$, piso

Teléfono: 3277300 Ext. 5145

editorial@ucatolica.edu.co

www.ucatolica.edu.co

http://publicaciones.ucatolica.edu.co/

Impresión:

JAVEGRAF

Calle 46A No82-54 Int. 2

Bogotá, D. C., Colombia

http://www.javegraf.com.co/index.php

Agosto de 2018

\section{Revista de Arquitectura \\ (Bogotá)}

Director

Werner Gómez Benítez

Editor

César Eligio-Triana

Editores de sección

(1) Myriam Stella Díaz Osorio

(1) Carolina Rodríguez-Ahumada

(1) Anna Maria Cereghino Fedrigo

\section{Equipo editorial}

Coordinadora editorial

María Paula Godoy Casasbuenas mpgodoy@ucatolica.edu.co

Diseño y montaje

Juanita Isaza

juanaisaza@gmail.com

Traductoras

Inglés

Erika Tanacs

etanacs25@gmail.com

Portugués

Roanita Dalpiaz

roanitad@gmail.com

Correctora de estilo

María José Díaz Granados M.

mariajose_dgm@yahoo.com.co

Página Web

Centro de investigaciones (CIFAR)

Distribución y canjes

Claudia Álvarez Duquino

calvarez@ucatolica.edu.co
Comité editorial y científico

Cultura y espacio urbano

Carlos Mario Yory, PhD

Universidad Católica de Colombia. Bogotá, Colombia

Sonia Berjman, $\mathrm{PhD}$

ICOMOS-IFLA, Buenos Aires, Argentina

Juan Carlos Pérgolis, MSc Universidad Piloto de Colombia. Bogotá, Colombia

Beatriz García Moreno, PhD

Universidad Nacional de Colombia. Bogotá, Colombia

Proyecto arquitectónico y urbano

Jean-Philippe Garric, PhD, HDR

Université Paris I Panthéon-Sorbonne. Paris, Francia

Debora Domingo Calabuig, PhD

Universidad Politécnica de Valencia, España

Dania González Couret, PhD

Universidad Tecnológica de La Habana, Cuba

Hugo Mondragón López, PhD Pontificia Universidad Católica de Chile. Santiago, Chile

Juan Pablo Duque Cañas, PhD

Universidad Nacional de Colombia. Bogotá, Colombia

Tecnología, medioambiente y sostenibilidad

Mariano Vázquez Espí, PhD

Universidad Politécnica de Madrid, España

Denise Helena Silva Duarte, PhD Universidade de São Paulo (USP), Brasil

Luis Carlos Herrera Sosa, PhD Universidad Autónoma de Ciudad Juárez, México

Claudio Varini, PhD

Universidad Católica de Colombia. Bogotá, Colombia

Luis Gabriel Gómez Azpeitia, PhD Universidad de Colima. Colima, México 


\section{Contenido}

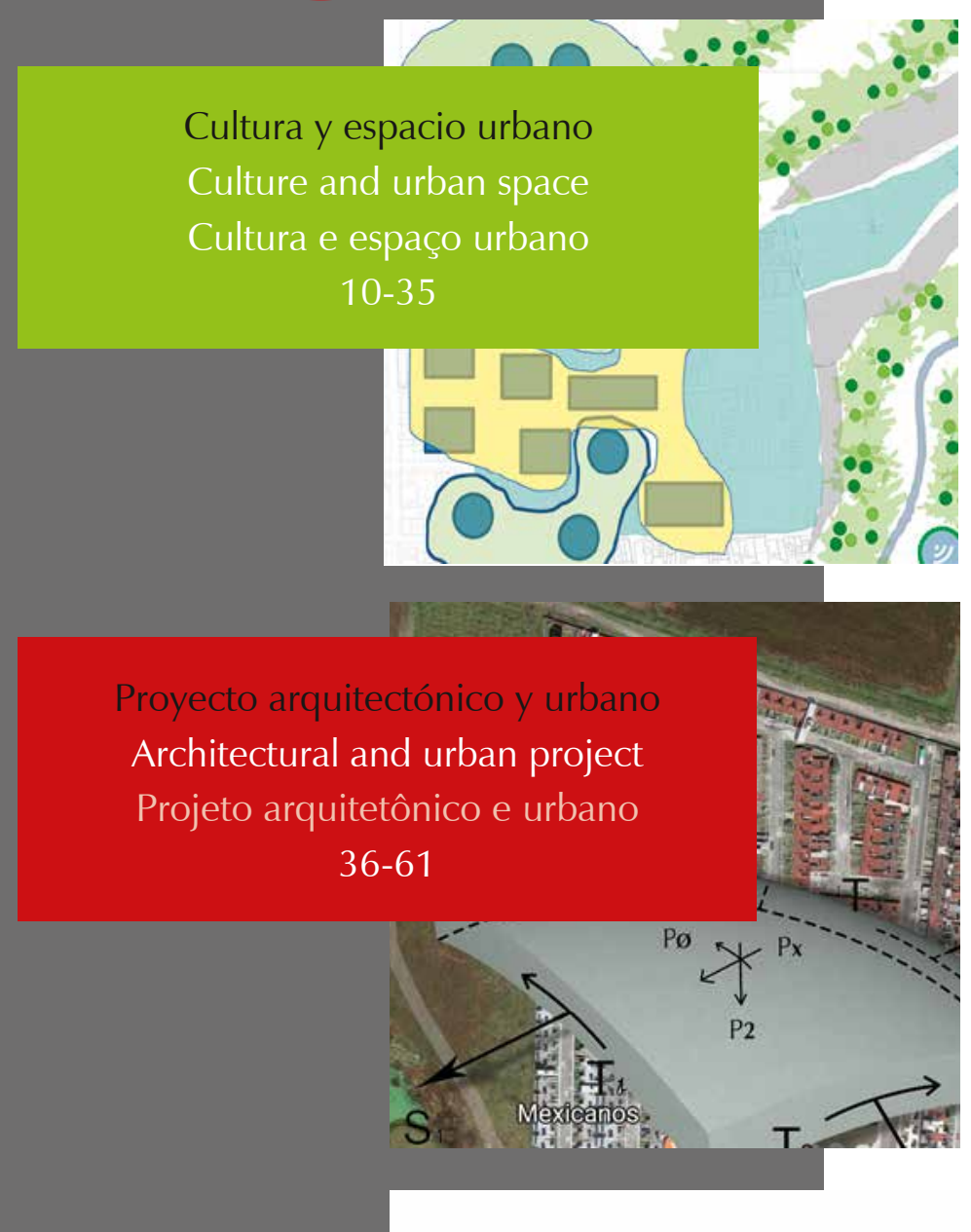

Tecnología, medioambiente

y sostenibilidad

Technology, environment and sustainability

Tecnologia, meio ambiente e sustentabilidade

62-89
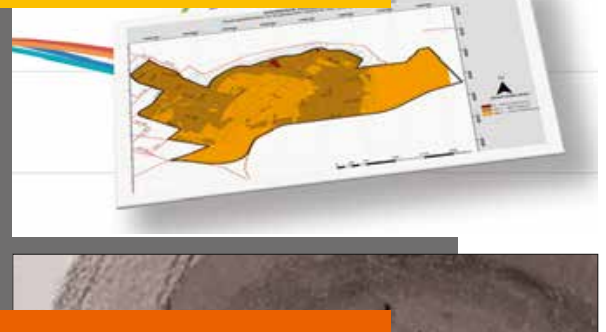

Desde la Facultad

From the Faculty

Da faculdade

90-109
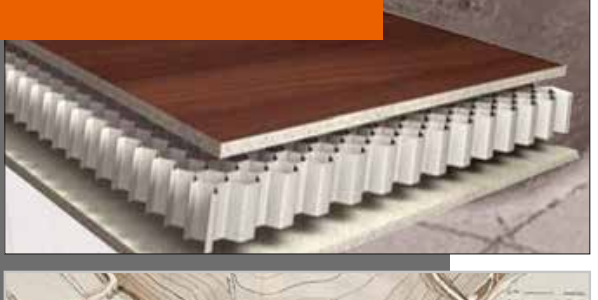

Textos

Texts

Textos

110-126

Los artículos científicos como herramienta de aprendizaje en las escuelas de arquitectura

Carolina Rodríguez-Ahumada

Pág. 3 ES

Paisaje urbano y espacio público como expresión de la vida cotidiana

Morella Briceño-Ávila

Pág. 10

\section{ES EN}

Habitar la quebrada: conformación de gradientes en las trazas vernaculares de los sectores altos de Valparaíso

\section{Omar Eduardo Cañete-Islas}

Juan Luis Moraga-Lacoste

Felipe Mateo López-Flores

Pág. 20

ES

Láminas cilíndricas en la arquitectura colombiana del siglo XX

Jorge Galindo-Díaz

Pág. 36

\section{ES EN}

Retórica simbólica en el espacio arquitectónico

Una mirada antropológica de la casa en la

sobremodernidad

Eska Elena Solano-Meneses

Pág. 51

ES

Ecoenvolventes: análisis del uso de fachadas ventiladas en clima cálido-húmedo

\footnotetext{
Sara Luciani-Mejía

Rodrigo Velasco-Gómez

Roland Hudson
}

Pág. 62

ES

Estrategias metodológicas de análisis urbano frente al cambio climático

Matriz para el diseño adaptativo en asentamientos informales

Adriana Patricia López-Valencia

Oswaldo López-Bernal

Pág. 78

ES

Muro panel térmico estructural compuesto

en guadua y cartón

Modelo experimental aplicado al clima de

la zona cafetera

Renato Cassandro-Cajiao

Pág. 90

\section{ES EN}

Continuidad y transformaciones de modelos

pedagógicos en la École Polytechnique (1867-1910)

Estelle Thibault

Traductores

Andrés Ávila-Gómez

Diana Carolina Ruiz

Pág. 110

ES 
La postulación de un artículo a la Revista de Arquitectura (Bogotá) indica que- el o los autores certifican que conocen y aceptan la política editorial, para lo cual firmarán en original y remitirán el formato RevArq FP00 Carta de originalidad.

La Revista de Arquitectura (Bogotá) maneja una política de Autoarchivo VERDE, según las directrices de SHERPA/RoMEO, por lo cual el autor puede:

- Pre-print del autor: Archivar la versión pre-print (la versión previa a la revisión por pares

- Post-print del autor: Archivar la versión post-print (la versión final posterior a la revisión por pares

- Versión de editor/PDF: Archivar la versión del editor - PDF/HTML/XLM en la maqueta de la Revista de Arquitectura (Bogotá).

El Autoarchivo se debe hacer respetando la licencia de acceso abierto, la integridad y la imagen de la Revista de Arquitectura (Bogotá), también se recomienda incluir la referencia, el vínculo electrónico y el DOI.

El autor o los autores son los titulares del Copyright (c) del texto publicado y la Editorial de la Revista de Arquitectura (Bogotá) solicita la firma de una autorización de reproducción del artículo (RevArq FP03 Autorización reproducción), la cual se acoge a la licencia CC, donde se expresa el derecho de primera publicación de la obra.

La Revista de Arquitectura (Bogotá) se guía por las normas internacionales sobre propiedad intelectual y derechos de autor, y de manera particular el artículo 58 de la Constitución Política de Colombia, la Ley 23 de 1982 y el Acuerdo 172 del 30 de septiembre de 2010 (Reglamento de propiedad intelectual de la Universidad Católica de Colombia)

Para efectos de autoría y coautoría de artículos se diferencian dos tipos: "obra en colaboración" y "obra colectiva". La primera es aquella cuya autoría corresponde a todos los participantes al ser fruto de su trabajo conjunto. En este caso, quien actúa como responsable y persona de contacto debe asegurar que quienes firman como autores han revisado y aprobado la versión final, y dan consentimiento para su divulgación. La obra colectiva es aquella en la que, aunque participan diversos colaboradores, hay un autor que toma la iniciativa la coordinación y realización de dicha obra. En estos casos, la autoría corresponderá a dicha persona (salvo pacto en contrario) y será suficiente únicamente con su autorización de divulgación.

El número de autores por artículo debe estar justificado por el tema, la complejidad y la extensión, y no deberá ser superior a la media de la disciplina, por lo cual se recomienda que no sea mayor de cinco. El orden en que se enuncien corresponderá a los aportes de cada uno a la construcción del texto, se debe evitar la autoría ficticia o regalada. Si se incluyen más personas que trabajaron en la investigación se sugiere que sea en calidad de colaboradores o como parte de los agradecimientos. La Revista de Arquitectura (Bogotá) respetará el número y el orden en que figuren en el original remitido. Si los autores consideran necesario, al final del artículo pueden incluir una breve descripción de los aportes individuales de cada uno de firmantes.

La comunicación se establece con uno de los autores, quien a su vez será el responsable de informar a los demás autores de las notificaciones emitidas por la Revista de Arquitectura (Bogotá).

En virtud de mantener el equilibro de las secciones y las mismas oportunidades para todos los participantes, un mismo autor puede postular dos o más artículos de manera simultánea; si la decisión editorial es favorable y los artículos son aceptados, su publicación se realizará en números diferentes.

\section{A Acceso abierto}

La Revista de Arquitectura (Bogotá), en su misión de divulgar la investigación y apoyar el conocimiento y la discusión en los campos de interés, proporciona acceso abierto, inmediato e irrestricto a su contenido de manera gratuita mediante la distribución de ejemplares impresos y digitales. Los interesados pueden leer, descargar, guardar, copiar y distribuir, imprimir, usar, buscar o referenciar el texto completo o parcial de los artículos o la totalidad de la Revista de Arquitectura (Bogotá).

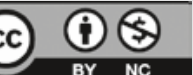

Esta revista se acoge a la licencia Creative Commons (CC BY NC de Atribución - No comercial 4.0 Internacional): "Esta licencia permite a otros entremezclar, ajustar y construir a partir de su obra con fines no comerciales, y aunque en sus nuevas creaciones deban reconocerle su autoría y no puedan ser utilizadas de manera comercial, no tienen que estar bajo una licencia con los mismos términos".

La Revista de Arquitectura es divulgada en centros y grupos de investigación, en bibliotecas y universidades, y en las principales facultades de Arquitectura mediante acceso abierto a la versión digital y suscripción anual al ejemplar impreso o por medio de canje, este último se formaliza mediante el formato RevArq FP20 Canjes

Para aumentar su visibilidad y el impacto de los artículos, se envían a bases de datos y sistemas de indexación y resumen (SIR) y, asimismo, pueden ser consultados y descargados en la página web de la revista.

La Revista de Arquitectura no maneja cobros, tarifas o tasas de publicación de artículo (Article Processing Charge-APC), o por el sometimiento de textos a la publicación.

\section{(1)Ética y buenas prácticas}

La Revista de Arquitectura se compromete a cumplir y respetar las normas éticas en todas las etapas del proceso de publicación. Los autores de los artículos publicados darán cumplimiento a los principios éticos contenidos en las diferentes declaraciones y legislaciones sobre propiedad intelectual y derechos de autor específicos del país donde se realizó la investigación. En consecuencia, los autores de los artículos postulados y aceptados para publicar, que presentan resultados de investigación, deben firmar la declaración de originalidad (formato RevArq FP00 Carta de originalidad).

La Revista de Arquitectura reconoce y adopta los principios de transparencia y buenas prácticas descritos por COPE, "Principles of Transparency and Best Practice in Scholarly Publishing" (2015).

El equipo editorial tiene la obligación de guardar la confidencialidad acerca de los artículos recibidos, y abstenerse de usar en sus propias investigaciones datos, argumentos o interpretaciones hasta tanto el artículo no sea publicado. También debe ser imparcial y gestionar los artículos de manera adecuada y en los plazos establecidos. La selección de revisores se hará con objetividad y estos deberán responder a la temática del artículo.

El editor, los autores y los revisores deben seguir las normas éticas internacionales definidas por el Committee on Publication Ethics (COPE), con el fin de evitar casos de:

- Fabricación, falsificación u omisión de datos.

- Plagio y autoplagio.

- Publicación redundante, duplicada o fragmentada.

- Omisión de referencias a las fuentes consultadas.

- Utilización de contenidos sin permiso o sin justificación.

- Apropiación individual de autoría colectiva.

- Cambios de autoría.

- Conflicto de interés (CDI) no revelado o declarado.

- Otras que pudieran surgir en el proceso de investigación y publicación. La fabricación de resultados se genera al mostrar datos inventados por los autores; la falsificación resulta cuando los datos son manipulados y cambiados a capricho de los autores; la omisión se origina cuando los autores ocultan deliberadamente un hecho o dato. El plagio se da cuando un autor presenta como ideas propias datos creados por otros. Los casos de plagio son los siguientes: copia directa de un texto sin entrecomillar o citar la fuente, modificación de algunas palabras del texto, paráfrasis y falta de agradecimientos; el autoplagio se da cuando el mismo autor reutiliza material propio que ya fue publicado, pero sin indicar la referencia al trabajo anterior. La revista se apoya en herramientas digitales que detectan cualquiera de estos casos en los artículos postulados, y es labor de los editores y revisores velar por la originalidad y fidelidad en la citación. La publicación redundante o duplicada se refiere a la copia total, parcial o alterada de un trabajo ya publicado por el mismo autor

En caso de sospechar de alguna mala conducta se recomienda seguir los diagramas de flujo elaborados por COPE (2008), con el fin de determinar las acciones correspondientes.

La Revista de Arquitectura se reserva el derecho de retractación de publicación de aquellos artículos que, posterior a su publicación, se demuestre que presentan errores de buena fe, o cometieron fraudes o malas prácticas científicas. Esta decisión se apoyará en "Retraction Guidelines" (COPE, 2009). Si el error es menor, este se podrá rectificar mediante una nota editorial de corrección o una fe de erratas. Los autores también tienen la posibilidad de solicitar la retractación de publicación cuando descubran que su trabajo presenta errores graves. En todos los casos se conservará la versión electrónica y se harán las advertencias de forma clara e inequívoca.

\section{A Privacidad y manejo de la información.} Habeas Data

Para dar cumplimiento a lo previsto en el artículo 10 del Decreto 1377 de 2013, reglamentario de la Ley 1581 de 2012, y según el Acuerdo 002 del 4 de septiembre de 2013 de la Universidad Católica de Colombia, "por el cual se aprueba el manual de políticas de tratamiento de datos personales":

La Universidad Católica de Colombia, considerada como responsable o encargada del tratamiento de datos personales, manifiesta que los datos personales de los autores, integrantes de los comités y pares revisores, se encuentran incluidos en nuestras bases de datos; por lo anterior, y en cumplimiento de las disposiciones legales vigentes, la Universidad solicitará siempre su autorización, para que en desarrollo de sus funciones propias como Institución de Educación Superior, en especial las relacionadas con la docencia, la extensión y la investigación, la Universidad Católica de Colombia pueda recolectar, recaudar, almacenar, usar, circular, suprimir, procesar, intercambiar, compilar, dar tratamiento, actualizar, transmitir o transferir a terceros países y disponer de los datos que le han suministrado y que han sido incorporados en las bases de datos de todo tipo que reposan en la Universidad.

La Universidad Católica de Colombia queda autorizada, de manera expresa e inequívoca, en los términos señalados por el Decreto 1377 de 2013, para mantener y manejar la información de nuestros colaboradores (autores, integrantes de los diferentes comités y pares revisores); así mismo, los colaboradores podrán ejercer sus derechos a conocer, actualizar, rectificar y suprimir sus datos personales, para lo cual se han dispuesto las siguientes cuentas de correo electrónico: 
La Revista de Arquitectura (Bogotá) recibe artículos de manera permanente. Los artículos se procesan a medida que se postulan, dependiendo el flujo editorial de cada sección.

El idioma principal es el español, y como opcionales están definidos el inglés, el portugués y el francés; los textos pueden ser escritos y presentados en cualquiera de estos.

Los artículos postulados deben corresponder a las categorías universalmente aceptadas como producto de investigación, ser originales e inéditos y sus contenidos responder a criterios de precisión, claridad y brevedad.

Como punto de referencia se pueden tomar las tipologías y definiciones del Índice Bibliográfico Nacional, Publindex (2010) que se describen la continuación:

1. Artículo de revisión: documento resultado de una investigación terminada donde se analizan, sistematizan e integran los resultados de investigaciones publicadas o no publicadas, sobre un campo en ciencia o tecnología, con el fin de dar cuenta de los avances y las tendencias de desarrollo. Se caracteriza por presentar una cuidadosa revisión bibliográfica de por lo menos 50 referencias.
2. Artículo de investigación científica y tecnológica: documento que presenta, de manera detallada, los resultados originales de proyectos terminados de investigación. La estructura generalmente utilizada contiene cuatro apartes importantes: introducción, metodología, resultados y conclusiones.

3. Artículo de reflexión: documento que presenta resultados de investigación terminada desde una perspectiva analítica, interpretativa o crítica del autor, sobre un tema específico, recurriendo a fuentes originales.

Adicional a estas tipologías, se pueden presentar otro tipo de artículos asociados a procesos de investigación-creación y/o investigación proyectual. En todos los casos se debe presentar la información suficiente para que cualquier investigador pueda reproducir la investigación y confirmar o refutar las interpretaciones defendidas y sea evidente el aporte a la disciplina.

En todos los casos se debe presentar la información suficiente para que cualquier investigador pueda reproducir la investigación y confirmar o refutar las interpretaciones defendidas.

\section{(A) Instrucciones para postular artículos}

Postular el artículo en la página web de la Revista de Arquitectura (Bogotá) y adjuntar comunicación escrita dirigida al editor RevArq_FP00 Carta de originalidad (debidamente firmada por todos los autores en original); de igual manera, se debe diligenciar el formato de hoja de vida RevArq FP01 Hoja de Vida (una por cada autor).

En la comunicación escrita el autor expresa que conoce y acepta la política editorial de la Revista de Arquitectura (Bogotá), que el artículo no está postulado para publicación simultáneamente en otras revistas u órganos editoriales y que no existe conflicto de intereses (ver modelo RevArq FP06 CDI) y que, de ser aceptado, concederá permiso de primera publicación, no exclusiva a nombre de la Universidad Católica de Colombia como editora de la revista.

Los artículos deben tener en cuenta las siguientes recomendaciones:

- En la primera página del documento se debe incluir:

Tírulo: no exceder 15 palabras

Subtítulo: opcional, complementa el título o indica las principales subdivisiones del texto.

Nombre del autor o autores: nombres y apellidos completos o según modelo de citación adoptado por el autor para la normalización de los nombres del investigador. Como nota al pie (máximo 150 palabras): formación académica, experiencia profesional e investigativa, vinculación laboral, código https://orcid.org/, premios o reconocimientos, publicaciones representativas e información de contacto, correo electrónico.

Filiación institucional: debajo del nombre se debe declarar la ins-titución en la cual se desarrolló el producto, de la cual recibió apoyo o aquella que respalda el trabajo investigativo.

Resumen: debe ser analítico, se redacta en un solo párrafo, da cuenta del tema, el objetivo, la metodología, los resultados y las conclusiones; no debe exceder las 150 palabras.

Palabras clave: cinco palabras o grupo de palabras, ordenadas alfabéticamente y que no se encuentren en el título o subtítulo; estas sirven para clasificar temáticamente al artículo. Se recomienda emplear principalmente palabras definidas en el tesauro de la Unesco (http://databases. unesco.org/thessp/), en el tesauro de Arte \& Arquitectura (C) (www.aatespanol.cl), o Vitruvio (http://vocabularyserver.com/vitruvio/)

También se recomienda incluir título, resumen y palabras clave en segundo idioma.

- La segunda página y siguientes deben tener en cuenta:

El cuerpo del artículo se divide en: Introducción, Metodología, Resultados y Discusión de resultados; posteriormente se presentan las Conclusiones, y luego las Referencias bibliográficas y los Anexos (método IMRYD). Las tablas y figuras se deben incorporar en el texto.

Descripción del proyecto de investigación: en la introducción se debe describir el tipo de artículo y brevemente el marco investigativo del cual es resultado y diligenciar el formato (RevArq FP02 Info Proyectos de Investigación).

TEXTO: todas las páginas deben venir numeradas y con el título de artículo en la parte superior de la página. Márgenes de $3 \mathrm{~cm}$ por todos los lados, interlineado doble, fuente Arial o Times New Roman de 12 puntos, texto justificado (Ver plantilla para presentación de artículos). La extensión de los artículos debe ser de alrededor de 5.000 palabras ( \pm 20 páginas, incluyendo gráficos, tablas, referencias, etc.); como mínimo 3.500 y máximo 8.000 palabras. Se debe seguir el estilo vigente y recomendado en el Manual para Publicación de la American Psychological Association (APA). (Para mayor información véase http://www.apastyle.org/)
Citas y notas al pie: las notas aclaratorias o notas al pie no deben exceder cinco líneas o 40 palabras, de lo contrario estas deben ser incorporadas al texto general. Las citas pueden ser:

Corta: (con menos de 40 palabras) se incorporan al texto y pueden ser: textuales (se encierran entre dobles comillas), parafraseo o resumen (se escriben en palabras del autor dentro del texto).

Cita textual extensa: (mayor de 40 palabras) debe ser dispuesta en un renglón y un bloque independiente con sangrías y omitiendo las comillas, no olvidar en ningún caso la referencia del autor (Apellido, año, página).

Referencias: como modelo para la construcción de referencias se emplea el estilo recomendado en el Manual para Publicación de la American Psychological Association (APA) (http://www.apastyle.org/).

Siglas: en caso de emplear siglas en el texto, las figuras o las tablas, se debe proporcionar la equivalencia completa la primera vez que se empleen y encerrarlas entre paréntesis. En el caso de citar personajes reconocidos se deben colocar nombres o apellidos completos, nunca emplear abreviaturas.

Figuras y tablas: las figuras (gráficos, diagramas, ilustraciones, planos, mapas o fotografías) y las tablas deben ir numeradas y contener título o leyenda explicativa relacionada con el tema del artículo, que no exceda las 15 palabras (Figura 1. xxxxx, Tabla 1. xxxx, etc.) y la procedencia (fuente: autor o fuente, año, página). Estas se deben referenciar en el texto de forma directa o entre paréntesis; se recomienda hacerlo con referencias cruzadas.

También se deben entregar en medio digital, independiente del texto, en formatos editables o abiertos. La marcación de los archivos debe corresponder a la incluida en el texto. Según la extensión del artículo se deben incluir de 5 a 10 gráficos. Ver guía para la búsqueda de imágenes de dominio público o bajo licencias Creative Commons (CC).

El autor es el responsable de adquirir los derechos o las autorizaciones de reproducción a que haya lugar para imágenes o gráficos tomados de otras fuentes, así como de entrevistas o material generado po colaboradores diferentes a los autores; de igual manera, se debe garantizar la protección de datos e identidades para los casos que sea necesario.

Fotografía: pueden ser entregadas en original para ser digitalizadas, de lo contrario se deben digitalizar con una resolución igual o superior a 300 dpi para imágenes a color y 600 para escala de grises. Los formatos de las imágenes pueden ser TIFF, PSD o JPG, y deben cumplir con las características expresadas en el punto anterior (figuras).

Planimetría: se debe entregar la planimetría original en medio digital, en lo posible en formato CAD, y sus respectivos archivos de plumas o en PDF; de no ser posible, se deben hacer impresiones en tamaño carta con las referencias de los espacios mediante numeración y lista adjunta. Deben tener escala gráfica, escala numérica, norte, coordenadas y localización. En lo posible, no deben contener textos, achurados o tramas.

Para más detalles, consultar el documento RevArq Parámetros para Autores Descripción en el portal web de la Revista de Arquitectura (Bogotá)

\section{Beneficios}

Como reconocimiento a los autores, se les hará envío postal de dos ejemplares de la edición impresa sin ningún costo y entregada en la dirección consignada en el formato de hoja de vida (RevArq FP01); adicionalmente, se enviará el vínculo para la descarga de la versión digital.

También se enviará una constancia informativa en la que se relaciona a publicación del artículo y, de manera opcional, se pueden detallar las fechas del proceso editorial y el arbitraje realizado. 
La selección de revisores se realiza de acuerdo con los siguientes criterios:

- Afinidad temática.

- Formación académica.

- Experiencia investigativa y profesional.

- Producción editorial en revistas similares o en libros resultado de investigación.

El proceso de arbitraje se basa en los principios de equidad e imparcialidad, y en los criterios de calidad y pertinencia.

El desarrollo de la revisión se realiza según el formato (RevArq FP10 Evaluación de artículos) y las observaciones que el revisor considere necesarias en el cuerpo del artículo. En cualquiera de los conceptos que emita el revisor (Aceptar, Publicable con modificaciones, Reevaluable o No publicable), y como parte de la labor formativa y de comunidad académica, el revisor hará sugerencias para mejorar el documento. El revisor podrá solicitar una nueva relectura del artículo después de los ajustes realizados por el autor.

El revisor también deberá diligenciar el formato RevArq FP01 Hoja de Vida, con el fin de certificar y soportar el proceso de revisión ante los SIR que así lo soliciten.

En el proceso de arbitraje se emplea el método doble ciego, los nombres del revisor no serán conocidos por el autor y viceversa. Con el fin de garantizar el anonimato del autor, al artículo postulado se le han podido suprimir nombres, instituciones o imágenes que puedan ser asociadas de manera directa al autor.

Aunque se procura el anonimato, una vez recibida la invitación como par revisor del artículo, el revisor debe cerciorarse de que no exista conflicto de intereses (CDI) o alguna limitante que afecte la revisión o que pueda ser vista como tal (lazos familiares, amistad o enemistad, vínculos contractuales o laborales, posiciones éticas, etc.), de presentarse esta situación se notificara al editor. (Ver modelo RevArq FP06 CDI).

Dada la confidencialidad del proceso de revisión, y considerando los derechos de autor y de propiedad intelectual que pueda haber sobre el material que se entrega, el revisor se compromete a mantener en absoluta reserva su labor, a limitar el uso de la obra entregada solo para el propósito designado y a devolver la documentación remitida una vez concluya la actividad.

El tiempo establecido para las revisiones de pares es de máximo un mes a partir de la confirmación de la recepción de la documentación. Ese plazo podrá ser modificado de mutuo acuerdo entre el editor y el revisor, siempre y cuando no afecte la periodicidad de la revista, la impresión o el tiempo para emitir una respuesta al autor.

Los revisores se acogerán a "COPE Ethical Guidelines for Peer Reviewers" de COPE.

\section{Beneficios}

Como retribución a los revisores se les hará envío postal de un ejemplar de la edición impresa sin ningún costo y entregada en la dirección consignada en el formato de hoja de vida. También, si es de interés para el revisor, podrá hacer la solicitud de alguna de las publicaciones editadas y presentes en el catálogo de publicaciones de la UNIVERSIDAD CATÓLICA DE COLOMBIA, previa aprobación de la Editorial y sujeto a la disponibilidad.

Si lo desea tendrá derecho a una constancia de la colaboración en la revisión de artículos, la cual solo contendrá el periodo en el cua se realizó la actividad. También tendrá la posibilidad de aceptar o no la publicación de su nombre, nacionalidad y nivel máximo de formación en la página web de la Revista de Arquitectura (Bogotá) en su calidad de colaborador.

\section{A Proceso de revisión por pares}

Luego de la postulación del artículo, el editor de la Revista de Arquitectura (Bogotá) selecciona y clasifica los artículos que cumplen con los requisitos establecidos en las directrices para los autores. El editor podrá rechazar en primera instancia artículos, sin recurrir a un proceso de revisión, si los considera de baja calidad o por presentar evidencias de faltas éticas o documentación incompleta.

Los artículos se someterán a un primer dictamen del editor, de los editores de sección y del Comité Editorial, teniendo en cuenta:

- Afinidad temática, relevancia del tema y correspondencia con las secciones definidas.

- Respaldo investigativo.

- Coherencia en el desarrollo del artículo, así como una correcta redacción y ortografía.
- Relación entre las figuras y tablas con el texto del artículo.

En esta revisión se verificará el nivel de originalidad mediante el uso de software especializado (Ithenticate o similar) y recursos digitales existentes para tal fin, también se observará la coherencia y claridad en los apartados del documento (modelo IMRYD) la calidad de las fuentes y la adecuada citación, esto quedará consignado en el formato (RevArq FP09 Revisión de artículos); esta información será cargada a la plataforma de gestión editorial y estará a disposición del autor.

En caso de que el artículo requiera ajustes preliminares, será devuelto al autor antes de ser remitido a revisores. En este caso, el autor tendrá veinte días para remitir nuevamente el texto con los ajustes solicitados.

Después de la preselección se asignan mínimo dos revisores especializados, quienes emitirán su concepto utilizando el formato (RevArq FP10 Evaluación de artículos) y las anotaciones que consideren oportunas en el texto; en esta etapa se garantizará la confidencialidad y el anonimato de autores y revisores (modalidad doble ciego)

Del proceso de revisión se emite uno de los siguientes conceptos que será reportado al autor:

- Aceptar el envío: con o sin observaciones.

- Publicable con modificaciones: se podrá sugerir la forma más adecuada para una nueva presentación, el autor puede o no aceptar las observaciones según sus argumentos. Si las acepta, cuenta con quince días para realizar los ajustes pertinentes.

- Reevaluable: cumple con algunos criterios y debe ser corregido. Es necesario hacer modificaciones puntuales y estructurales al artículo. En este caso, el revisor puede aceptar o rechazar hacer una nueva lectura del artículo luego de ajustado.

- No publicable: el autor puede volver a postular el artículo e iniciar nuevamente el proceso de arbitraje, siempre y cuando se evidencien los ajustes correspondientes.

En el caso de presentarse diferencias sustanciales y contradictorias en los conceptos sobre la recomendación del revisor, el editor remitirá el artículo a un revisor más o a un miembro del Comité Editorial quien podrá actuar como tercer árbitro, con el fin de tomar una decisión editorial sobre la publicación de artículo.

Los autores deberán considerar las observaciones de los revisores o de los editores, y cada corrección incorporada u omitida debe quedar justificada en el texto o en una comunicación adjunta. En el caso que los autores omitan las indicaciones realizadas sin una argumentación adecuada, el artículo será devuelto y no se dará por recibido hasta que no exista claridad al respecto. El editor respetará la independencia intelectual de los autores y a estos se les brindará el derecho de réplica en caso de que los artículos hayan sido evaluados negativamente y rechazados. Los autores, con su usuario y contraseña, podrán ingresar a la plataforma de Gestión Editorial, donde encontrarán los conceptos emitidos y la decisición sobre el artículo.

El editor y el Comité Editorial se reservan el derecho de aceptar o no la publicación del material recibido. También se reservan el derecho de sugerir modificaciones de forma, ajustar las palabras clave o el resumen y de realizar la corrección de estilo. El autor conocerá la versión final del texto antes de la publicación oficial del mismo.

Cuando un artículo es aceptado para su publicación, el autor debe firmar la autorización de reproducción (RevArq FP03 Autorización reproducción). Para más información ver: Política de derechos de autor

\section{Notas aclaratorias:}

La Revista de Arquitectura (Bogotá) busca el equilibrio entre las secciones, motivo por el cual, aunque un artículo sea aceptado o continúe en proceso de revisión, podrá quedar aplazado para ser publicado en un próximo número; en este caso, el autor estará en la posibilidad de retirar la postulación del artículo o de incluirlo en el banco de artículos del próximo número.

El editor y los editores de sección de la Revista de Arquitectura (Bogotá) son los encargados de establecer contacto entre los autores y revisores, ya que estos procesos se realizan de manera anónima.
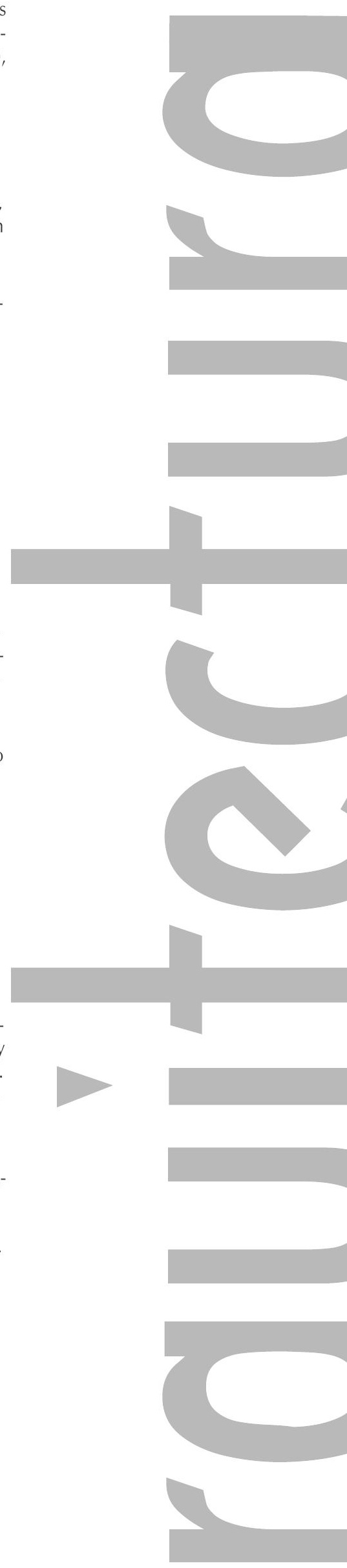

\section{.}

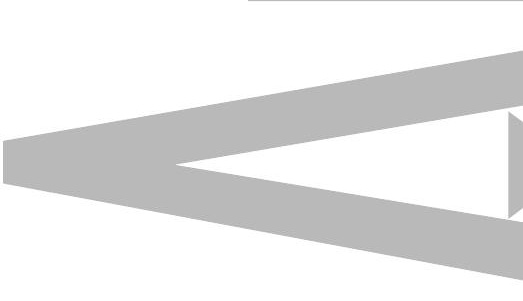


Los artículos científicos como herramienta de aprendizaje en las escuelas de arquitectura

نं Scientific articles as a learning tool in architecture schools

$\ll \quad$ Os artigos científicos como ferramenta de aprendizagem

nas escolas de arquitetura

Carolina Rodriguez-Ahumada

Paisaje urbano y espacio público como expresión 으 de la vida cotidiana

Urban landscape and public space as an expression of everyday life

نั Paisagem urbana e espaço público como expressão da vida cotidiana

Habitar la quebrada: conformación de gradientes en las trazas 을 vernaculares de los sectores altos de Valparaíso

Inhabiting the ravine: Gradient configuration in the vernacular layouts of the

¿ higher sectors of Valparaíso

Habitar a quebrada: conformação de níveis nos traçados vernaculares dos setores altos de Valparaíso

\section{Omar Eduardo Canete-Islas}

Juan Luis Moraga-Lacoste

Felipe Mateo López-Flores

Láminas cilíndricas en la arquitectura colombiana del siglo $X X$ Cylindrical shells in Colombian architecture in the 20th century

Estruturas laminares cilíndricas na arquitetura colombiana do século $X X$ 这 Jorge Galindo-Díaz

Retórica simbólica en el espacio arquitectónico. Una mirada antropológica de la casa en la sobremodernidad

in Symbolic Rhetoric in the Architectural Space: An Anthropological View of the

ن House in the Age of Supermodernity

Retórica simbólica no espaço arquitetônico. Um olhar antropológico da casa na sobremodernidade

\section{Eska Elena Solano-Meneses}

Ecoenvolventes: análisis del uso de fachadas ventiladas en clima ㅈ cálido-húmedo

نं Eco-friendly coverings: Analysis of the use of ventilated facades in hot, humid

ن⿺ weather

Ecoenvolventes: análise do uso de fachadas ventiladas em clima quente úmido

Sara Luciani-Meía

Rodrigo Velasco-Gómez

Roland Hudson

Estrategias metodológicas de análisis urbano frente al cambio œ climático. Matriz para el diseño adaptativo en asentamientos $\stackrel{\infty}{\text { informales }}$

Methodological strategies for urban analysis in the face of climate change. An adaptive design matrix for informal settlements

Estratégias metodológicas de análise urbana ante mudanças climáticas. Matriz para o desenho adaptativo em assentamentos informais

Adriana Patricia López-Valencia

Muro panel térmico estructural compuesto en guadua y - cartónModelo experimental aplicado al clima de la zona cafetera

․ Structural thermal panel wall composed of bamboo and cardboard.

Experimental model applied to the climate of the Coffee Region

$\ltimes$ Muro painel térmico estrutural composto de bambu e papelão. Modelo experimental aplicado ao clima da zona cafeeira

\section{Renato Cassandro-Cajiao}

Continuidad y transformaciones de modelos pedagógicos en la École Polytechnique (1867-1910)

으 Continuity and transformations of teaching models at the École Polytechnique

二 (1867-1910)

ن Continuidade e transformações de modelos pedagógicos na École

¿ Polytechnique (I867-1910) 